\title{
S5ynthesis
}

International Scientific Conference of IT and Business-Related Research

\section{LMS OKRUŽENJE U FUNKCIJI REALIZACIJE CILJEVA KOMUNIKATIVNO- INTERAKTIVNOG ASPEKTA NASTAVE STRANIH JEZIKA}

\author{
THE USE OF LMS ENVIRONMENT FOR THE REALIZATION OF OBJECTIVES RELATED TO \\ COMMUNICATIVE-INTERACTIVE APPROACH IN FOREIGN LANGUAGE TEACHING
}

\author{
Sonja Urošević, Biljna Tešić, Ivana Damnjanović, Lora Petronić Petrović \\ Univerzitet Singidunum, Poslovni fakultet, Valjevo, Srbija
}

\begin{abstract}
Apstrakt:
U ovom radu su prikazana različita LMS okruženja (Learning Management System) sa aspekta njihove funkcije u cilju adekvatne primene didaktičkih principa u nastavi stranih jezika. Zahtevi koji se postavljaju pred obrazovanje u XXI veku ne odnose se samo na obezbeđenje kvaliteta znanja i veština kao ishoda obrazovnog procesa, već i na sniženje troškova i veću dostupnost korisnicima. U skladu sa eksplorativnim, praktično orijentisanim, demokratičnim, ali i individualnim pristupom podučavanju i učenju, kako u nastavi stranih jezika, tako i u usavršavanju nastavnika, sve veću primenu nalaze i sistemi za upravljanje online učenjem. Uspešno korišćenje platformi za učenje podrazumeva ne samo poznavanje pojedinih funkcija alata koje one obuhvataju, već i vladanje metodama i tehnikama njihove adekvatne upotrebe radi ostvarenja ciljeva specifičnih za nastavu jezika. U radu je objašnjen pojam elektronskog učenja, analizirane su različite platforme za elektronsko učenje i njihovo funkcionisanje u odnosu na principe kreiranja online-zadataka, uloga sinhronih i asinhronih alata u kontekstu učenja stranih jezika kao i odgovarajuće metode tokom određenih faza nastavnog procesa.
\end{abstract}

\section{Ključne reči:}

LMS, e-učenje, strani jezici, didaktički principi, alati za e-obrazovanje.

\section{UVOD}

Razvojem interneta i savremenih informacionih tehnologija snižavaju se barijere kreiranja i distribucije obrazovnog softvera što predstavlja značajne resurse za široku primenu aktivnih sadržaja u nastavnom procesu. U tom kontekstu dosta napora se ulaže na povećanje nivoa interaktivnosti i u nastavi stranih jezika. Modeli interakcija uz pomoć kompjutera u kojima se ogledaju odgovarajući pedagoško-psihološki i didaktičko-metodički zahtevi (ili logika tih zahteva) omogućuju primenu specifičnih nastavnih strategija. Upotreba novih medija i obrazovnog softvera omogućava spoj klasičnog i interaktivnog, osnosno tradicionalnog i modernog.

Definisanje i razvoj strategiju e-učenja, podržane adekvatnim softverskim rešenjima, sa fokusom na krajnje korisnike i njihove potrebe, predstavlja osnovu za postizanje najoptimalnijih i efektivnih rezultata u svakom obrazovnom procesu, pa tako i u nastavi stranih jezika.

\begin{abstract}
:
The aim of this paper is to present different LMS (Learning Management System) environments in terms of their functions to insure adequate application of didactic principles of the foreign languages teaching process. Demands concerning education in the 21 st century do not relate only to the provision of knowledge and skills as the outcome of the education process, but also to the reduction of costs and greater availability to users. In accordance with explorative, practically oriented, democratic, and individual approach to teaching and learning, both in foreign language teaching and teaching staff training, there is a growing tendency in use of online Learning Management Systems. However, the successful use of learning platforms requires not only knowledge of certain functions of tools they cover, but also the ability to use the appropriate methods and techniques in order to achieve the specific language teaching objectives.

The paper explains the concept of e-learning, analyses various elearning platforms and their functioning in relation to the principles of designing online tasks, the role of synchronous and asynchronous tools in the context of foreign language learning and the appropriate methods during certain stages of the teaching process.
\end{abstract}

\section{Key words:}

LMS, e-learning, foreign languages, didactic principles, courseware tools.

Bez obzira na različite tehnološke mogućnosti za prezentovanje obrazovnih sadržaja i savremenost multimedije i interneta, treba imati u vidu njihovu funkcionalnost u obrazovnom i pedagoškom smislu, dostupnost s obzirom na raspoložive resurse i isplativost imajući u vidu mogućnost postizanja jednakih ili boljih obrazovnih rezultata alternativnim sredstvima.

Postoji veliki broj platformi za e-učenje, ali njihov izbor zavisi od ciljeva učenja, ciljne grupe, pristupa i vrste sadržaja. Važno je znati kako se koristi e-learning okruženje i kakvi su uticaji primene savremenih veb-alata i servisa na specifičnosti ishoda učenja u nastavi stranih jezika.

\section{POJAM E-UČENJA I ODGOVARAJUĆIH ONLINE-AKTIVNOSTI (E-TIVITY)}

Elektrinsko učenje (e-learning) je način učenja, odnosno izvođenja edukativnog programa elektronskim putem, primenom savremenih informaciono komunikacionih tehnologija, 
najčešće putem interneta. „E-učenje podrazumeva svaki oblik edukacije u kome se obrazovni sadržaj isporučuje u elektronskoj formi" (Brown et al, 2003). Predstavlja obrazovni proces koji, u vremenu modernizacije obrazovne tehnologije kao sastavnog dela nastavnog procesa, pretpostavlja mogućnost prilagođavanja individualnim potrebama i različitim stilovima učenja. Upotreba elektronskih medija, edukacione tehnologije i informaciono komunikacione tehnologije (ICT-Information Communications Technology) u obrazovanju su pretpostavka elektronskog učenja, ali one same po sebi ne predstavljaju $e$ learning, već samo medijum za dostavu sadržaja i organizaciju aktivnosti.

E-učenje je rezultat kvalitetnih i progresivnih dostignuća pedagoške tehnologije koje se zasniva na principima slobodnog učenja, korišćenjem računara u obrazovnim programima i savremenih ICT, pre svega interneta. "Učenje je organizovano kao proces dijaloga u virtuelnim učionicama, što podrazumeva razdvojenost mentora od studenta/učenika u prostoru i (ili) vremenu." (Perraton, 2000). Američka asocijacija za učenje na daljinu (The United States Distance Learning Association) definiše pojam e-učenja kao "dostizanje znanja i veština u virtuelnom okruženju kroz dostavljene informacije i uputstva, primenom različitih tehnologija i ostalih formi učenja na daljinu".

Sa aspekta adaptivnosti sistem elektronskog obrazovanja se definiše kao adaptivan, ako je u mogućnosti da prati aktivnosti svojih učesnika, interpretira ih na osnovu oblasno-specifičnih modela, otkriva zahteve i preferencije u skladu sa prethodno uočenim aktivnostima, precizno ih reprezentuje u povezanim modelima i deluje prema otkrivenom znanju o učesnicima i oblastima, da bi dinamički upravljao procesom učenja ( $\mathrm{Pa}-$ ramythis \& Loidl-Reisinger, 2004).

Prilikom kreiranja virtuelnog okruženja za učenje stranih jezika neophodno je dakle postaviti ključna pitanja koja se tiču procesa učenja generalno: Kako funkcioniše učenje? Koji faktori utiču na efikasnost učenja? Koje su tehnike učenja najadekvatnije za postizanje određenih ciljeva?

U oblasti didaktike nastave stranih jezika se nakon ere komunikativne metode profiliraju koncepti koji u nastavnom procesu integrišu interaktivni i holistički pristup učenju sa fokusom na pojedinom učeniku. Međutim, zahtevi koji se u XXI veku stavljaju pred proces obrazovanja odnose se kako na usko stručne tako i na uslove koji se tiču ekonomičnosti, s obzirom na smanjenje troškova, jednaku dostupnost velikom broju korisnika nezavisno od njihovog mesta stanovanja i vremena koje im stoji na raspolaganju, uz obezbeđenje visokog kvaliteta nastave. To je dovelo do velikih očekivanja od elektronskog učenja i buma u razvoju rafiniranih veb-tehnologija. Budući da nisu svi inovativni digitalni alati i virtuelna okruženja sami po sebi doneli direktno unapređenje rezultata učenja, postavlja se pitanje na koji način se može obezbediti održivost obrazovanja u veb-okruženju. U tom smislu se akcenat stavlja, pored pitanja kvaliteta sadržaja koji se posreduje, prevashodno na način, odnosno nastavne metode uz pomoć kojih se ti sadržaji obrađuju. Ključnu ulogu u tom kontekstu imaju dakle aktivnosti koje u virtuelnom okruženju dovode do ispunjenja ciljeva učenja, što znači da one treba da budu zasnovane na principima navedenog interaktivnog, holističkog pristupa nastavi stranih jezika, istovremeno vodeći računa o potrebama, sposobnostima i tipovima pojedinih učenika. Gilly Salmon, australijska profesorka koja se već dvadeset godina bavi istraživanjem u ovoj oblasti, takve aktivnosti naziva „E-tivities“ i definiše ih kao zadatke za aktivno i interaktivno elektronsko učenje koji poseduju određene karakteristike. „E-tivity“ treba da bude motivišuća, da ima jasno određen cilj i da rezultira izvesnim napretkom. Pretpostavka je da te aktivnosti mogu da kreiraju sami nastavnici, da su jednostavne za korišćenje sa strane učenika i da pri tom ne izazivaju dodatne troškove (Salmon, 2002, str. 17). Gilly Salmon naglašava kao prednost mogućnost asinhrone interakcije između učesnika, koja se odvija prevashodno pisanim putem. Ono što ovako shvaćene aktivnosti ne pokrivaju je specifičnost ciljeva nastave stranih jezika, jer oni, pored pisanih, podrazumevaju i razvijanje usmenih veština, zbog kojih je potrebno obezbediti i uslove za sinhrono učenje. Međutim, slični metodički postupci se mogu primeniti i na razvijanje usmene komunikacije, tj. veština govora i slušanja.

\section{INTERAKCIJA I E-UČENJE}

\subsection{PRINCIP INTERAKTIVNOSTI U NASTAVNOM PROCESU}

Sposobnost korišćenja jezika je naročito podstaknuta kada je pažnja učesnika u komunikaciji fokusirana na prenošenje i primanje poruka koje sadrže za njih relevantne informacije (Rivers, 1987, str. 4). Ovakvo shvatanje komunikativne interakcije se ne podudara sa frontalno realizovanom nastavom, gde je inicijator komunikacije uglavnom nastavnik. Princip interaktivnosti dolazi do potpunog izražaja onda kada se nastavne aktivnosti prenesu na učenike, u vidu grupnog ili rada u paru, vežbi sa ulogama i različitih jezičkih igara. Ova takozvana tehničko-komunikativna dimenzija nastave stranih jezika predstavlja svojevrsni nastavak komunikativne metode osamdesetih godina, čiji su ciljevi bili pragmatično-funkcionalne prirode (Weber, 1998, str. 6-7).

Pojam interakcije $\mathrm{u}$ nastavnom procesu se u međuvremnu proširio i na takve interpersonalne odnose koji omogućavaju međusobnu razmenu kako na verbalnom, tako i na socijalnom i emocionalnom planu. Dok je komunikativni koncept bio uglavnom usmeren na aktivnosti koje su imale za cilj verbalni izraz i njegovo razumevanje, princip interakcije u procesu učenja uzima u obzir i socijalno psihološke postavke prema kojima su čovekovi misaoni procesi, doživljaji i emocije kao i ponašanje povezani sa njegovom socijalnom sredinom. U ovom kontekstu se naglasak stavlja na ulogu grupe kao na motivacioni potencijal, jer odnos sa drugima može da unapredi odnosno uspori ili omete proces učenja.

Da bi nastavne aktivnosti zadovoljile te zahteve, napuštaju se nasleđene komunikativne i interaktivne navike kako nastavnika, tako i učenika. Koncept takozvane „tematski centrirane interakcije" (Cohn, 2009) predstavlja preuzimanje odgovornosti za svoje učešće u nastavnim aktivnostima, što podrazumeva između ostalog i napuštanje modela učenja u kom je nastavnik jedini autoritet. Učenici se ohrabruju ne samo da iskažu svoje mišljenje u vezi sa usko nastavnim sadržajem, već da tematizuju i negativne emocionalne aspekte procesa učenja, kao što su npr. dosada, frustracija ili nedostatak motivacije.

Za takav pristup je nepohodno, pored jezičkih sadržaja, obezbediti i aktivnosti koje će doprineti osveštavanju grupne strukture. Da bi se kontakti unutar grupe optimirali, potrebno je ponuditi takve zadatke koji će dominantne članove grupe senzibilizarati i za potrebe periferne podgrupe, kako bi svi dobili šansu da participiraju u procesu učenja.

Važan vid interaktivnog pristupa je i podsticanje učenika na donošenje odluka. Simulirajući važne životne situacije, oni koriste strani jezik u cilju prenošenja informacija, razmatranja alternativa, sklapanja kompromisa, posredovanja u konfliktnim situacijama, itd.

Tematizovanje fenomena kao što su grupna struktura, dominacija i otpor u okviru grupe, uloga emotivnog faktora u pro- 
cesu učenja doprinose jačanju sposobnosti kooperativnog rešavanja problema. Takav vid učenja ukida anonimnost pojedinca, jer je baziran na mobilisanju ne samo kognitivnih potencijala čoveka svedenog na ulogu učenika, već uključuje i mnoge druge vitalne sposobnosti.

Ono što interaktivnoj nastavi daje posebnu dimenziju realnosti je važnost feedback-a, odnosno povratne informacije, koja se ne odnosi samo na rezultate stručno-predmetne nastave, već i na učešće pojedinaca kao realnih osoba. U postupku davanja povratnih informacija se upoređuje slika pojedinca o samom sebi sa slikom koju o njemu imaju drugi. Ona se na taj način relativira i eventulano koriguje, što opet otvara prostor za nove uvide, između ostalog i u odnosu na poboljšanje učinka učenja.

\subsection{CILJEVI I FAZE E-UČENJA}

Za razliku od nastave koja se realizuje uživo, virtuelno okruženje zahteva da, u cilju efikasnog učenja sa odgovarajućim ishodima i optimalnim rezultatima, sadržaji i zadaci budu prezentovani i koncipirani tako da omoguće interakciju između učesnika i moderatora s jedne strane, i učesnika međusobno s druge. Glavni zadatak moderatora se sastoji u tome da pokrene proces učenja, da ga inicira nekom interesantnom „varnicom“ (Salmon, 2004, str. 19), bez obzira da li je on autor sadržaja koji prenosi, ili ne. Razmenom mišljenja putem mejla, četa i foruma svi učesnici stupaju u kontakt što dovodi do aktiviranja jezičkog znanja i rešenja zadatka.

Pretpostavka za upešno e-učenje je dobro strukturisan proces online-nastave, koji Gilly Salmon predstavlja na osnovu modela sa pet nivoa - das 5-Stufen-Modell (Salmon, 2004, str. 27), koji pruža optimalan okvir za realizaciju principa interaktivnosti primenom odgovarajući online-aktivnosti („E-tivity“), vodeći računa o stalnom održanju motivacije polaznika (Slika 1).

Taj model se sastoji od sledećih pet nivoa:

1. Pristup i motivacija: Sa tehničke strane se na ovom nivou uspostavlja sistem i obezbeđuje pristup. Zadatak moderatora je da pozdravi učesnike i da ih ohrabri u cilju međusobnog upoznavanja.

2. Online-socijalizacija: Tehnički aspekat se sastoji od slanja i primanja priloga, koji se na nivou moderacije odnosi na zadavanje takvih online-aktivnosti da bi se učesnici privikli na novo virtuelno okruženje i različite kulturne i socijalne navike u učenju.
3. Razmena informacija: Na trećem nivou se odvija traženje novih informacija i kooperativno izvođenje zadataka uz prilagođavanje softvera pojedinačnim potrebama. Zadatak moderatora je da pri tom pruži neophodnu pomoć, koristeći odgovarajući nastavni materijal.

4. Konstrukcija znanja: Sa tehničke strane je na ovom nivou potrebno obezbediti alate za razmenu mišljenja i diskusiju, za koju moderator bira online-aktivnosti koji podstiču procesni karakter razvoja znanja.

5. Razvoj: Na petom nivou tehnička podrška predviđa informacije o dodatnim resursima izvan virtuelne učionice, dok je zadatak moderatora da motiviše učesnike da preuzmu odgovornost za svoje učenje i da ideje koje su dobili učestvujući u online-aktivnostima na prethodnim nivoima edukacije primene u praksi.

Proces interakcije koji odgovara principima interaktivnog pristupa učenju i podučavanju se sukcesivno izgrađuje i intenzivira u svakoj narednoj fazi ovog modela elektronskog učenja $\mathrm{u}$ virtuelnom okruženju.

\subsection{SINHRONA I ASINHRONA INTERAKCIJA}

Elektronsko učenje se, u odnosu na različite načine prezentacije sadržaja, formata medija, načina isporuke sadržaja, a posebno prirode interakcije koja se ostvaruje između učesnika u tom vidu učenja i predavača može svrstati u dve kategorije: asinhrono i sinhrono.

Kod asinhronog načina učenja uloga nastavnika je statička, tako što nastavnik u elektronskoj

formi postavi informacije na veb-stranicu, a pojedini učenici i nastavnik ne moraju u isto vreme biti onlajn. Nastavni materijal se prezentuje putem interneta, veb-prezentacija, audio i video prezentacija, a interakcija između učesnika nastavnog procesa se obavlja putem elektronske pošte, debatnih grupa, foruma i dr. Asinhrono učenje uvažava individualne razlike učenika i dozvoljava učeniku sa većim predznanjem da brže napreduje. Dodatna prednost je ta što učesnici raspored obavljanja zadataka prilagođavaju svom raspoloživom vremenu i dnevnom ritmu, što istovremeno pruža mogućnost učešća u edukaciji polaznicima iz različitih vremenskih zona. Ovaj vid rada smanjuje troškove i povećava ekonomičnost nastavnog procesa, ali omogućava i potpunu aktuelnost, jer se zastarele informacije mogu veoma brzo dopuniti ili zameniti novim. Najčešće mogućnosti

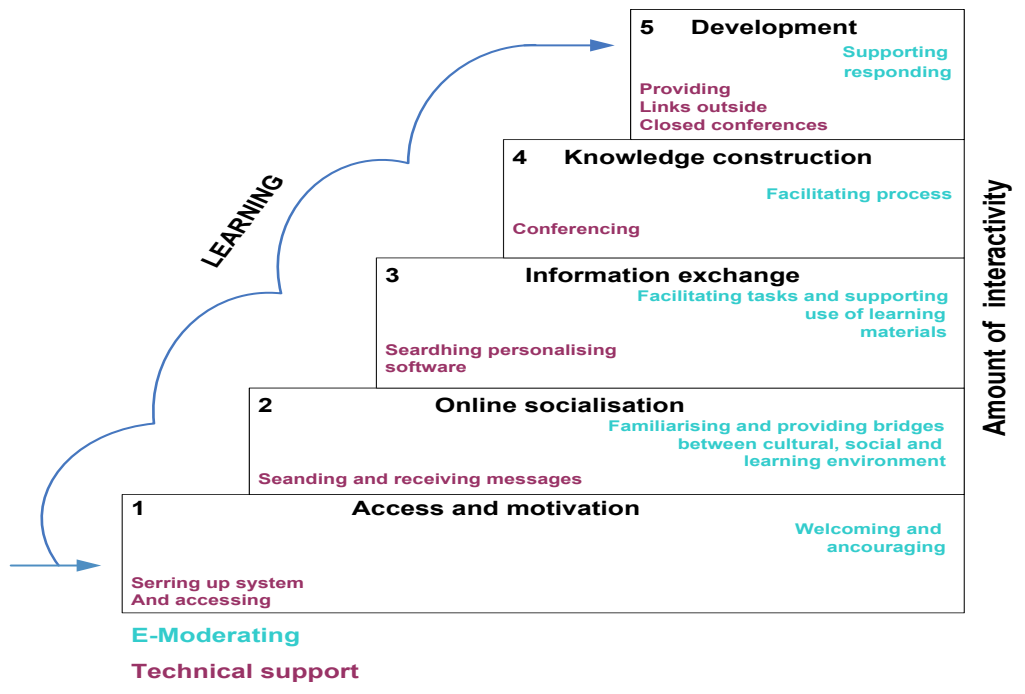

Slika 1: Faze e-učenja

Izvor: prilagođeno prema http://www.gillysalmon.com/five-stage-model.html 
asinhrone komunikacije su: e-pošta, veb-forum ili diskusione grupe, news-grupe - javni forumi koji koriste Usenet-system, Wiki-Web, blog, podkast.

Sinhrona interakcija se odvija bez značajnog vremenskog odstupanja, tako što polaznici istovremeno učestvuju u nastavnom procesu. Alati koji se koriste za sinhronu komunikaciju su chat, veb-telefonija (Skype), društvene mreže, Instant Massaging, video-konferencije, itd.

\section{INTERNET-SERVISI I SADRŽAJI U FUNKCIJI E-UČENJA}

Neki od najzasupljenijih internet servisa i sadržaja koji obezbeđuju efektivnu realizaciju principa interaktivnosti u procesu e-učenja detaljnije su opisani u nastavku teksta.

Elektronska pošta (e-mail) je najjednostavniji oblik asinhrone interakcije čije su prednosti: jednostavnost pri korišćenju, privatnost u komunikaciji, dovoljno vremenskog prostora za razmišljanje i odgovor.

Cirkularna pošta (Mailing list) je servis sa sličnim oblikom interakcije kao e-mail koji obezbeđuje jednostavnost u korišćenju, prilagođenost radu s grupom, deljenje učesnika u nekoliko manjih grupa u skladu sa određenim individualnim sklonostima i karakteristikama.

Diskusione grupe (Forum) su sajtovi ili delovi većeg sajta gde se na osnovu sličnog interesovanja mogu izneti mišljenja, komentari, postavljati pitanja ili odgovarati na pitanja. Na forumima se razjašnjavaju nedoumice, razmenjuju mišljenja, vode javne rasprave a moguće je otvoriti vlastitu diskusionu grupu po određenoj temi čime se dodatno poboljšava komunikacija korisnika.

Interaktivni razgovor na Internetu (Internet Relay ChatIRC) je jedan od najčešćih i najpopularnijih oblika sinhrone komunikacije baziran na tekstualnim porukama preko interneta ili intraneta u realnom vremenu. Omogućava interaktivni razgovor velikog broja korisnika sa približno jednakim znanjem, čime se podstiče ravnopravnost učesnika, objektivnost ocene i mogućnost nadoknađivanja propuštenog sadržaja.

Video-konferencije (Video Conferencing Instruction) su oblik sinhrone komunikacije u kojoj se uživo snima i prenosi audio i video materijal. Video-konferencijsko predavanje ponekad se prenosi i kao emitovanje na vebu (webcasting). Snimljeni audio-vizuelni sadržaji dostupni na zahtev (Video-on-Demand) mogu sadržati video-zapise predavanja, kurseve, prezentacije, kao i posebno snimljene i režirane edukativne video-zapise u različitim okruženjima.

Tekstualni i drugi sadržaji u neinteraktivnom i interaktivnom obliku (PDF dokumenti, Word ili PowerPoint datoteke, knjige u HTML formatu, objavljivanje dokumenata na Google Docs ili multimedijalnih obrazovnih sadržaja na YouTube-u ili Flickr-u, wiki tekst editor, itd.) predstavljaju najazastupljeniji obrazovni oblik sadržaja u e-učenju.

Testovi, kvizovi, igre, različiti zadaci za uvežbavanje i dr., su primer interaktivnih načina provere usvojenih znanja. Ovako oblikovani obrazovni sadržaji omogućavaju automatizaciju feedback-a (povratne informacije) polaznicima o njihovoj uspešnosti u usvajanju obrazovnih sadržaja, unose raznolikost u obrazovni proces, animiraju polaznike, omogućuju interakciju a kroz on-line testove polaznici mogu izvršiti samoprocenu znanja uz mogućnost automatskog ocenjivanja s drugima.

Blog je vrsta veb-sajta i značajan alat za realizaciju e-obrazovanja (npr. tematski blog, link blog) putem kojih se mogu ostvariti određeni ciljevi e-learning-a kao što je to slučaj i sa diskusionim grupama ili chat-om. Blog se pokazao kao izvan- redan komplement tradicionalnoj nastavi u pogledu obaveštenosti studenata ali prevashodno u unapređenju komunikacije i podizanju motivacije i drugih afektivnih činilaca učenja stranog jezika.

\section{LMS OKRUŽENJE I ALATI ZA E-OBRAZOVANJE}

Sistemi, koji upravljaju e-learning okruženjem nazivaju se LMS-sistemima (Learning Management System). Pored LMSa, u upotrebi su i sistemi za kreiranje obrazovnih sadržaja i upravljanje učenjem (Learning Content Management System - LCMS), koji su prošireni eksternim alatima, prilagođenim za kreiranje nastavnih materijala u cilju inteniziviranja njihove personalizacije (Course Authoring Tools ili Content Development Tools). U proteklom vremenu stvoreno je mnogo takvih sistema, kako komercijalnih tako i otvorenog koda, ali nije oformljen jedinstven standard koga bi se morali pridržavati da bi se nazvali LMS ili LCMS-om. Tačnije, LMS-sistemi objedinjuju sve potrebne alate za implementiranje e-učenja kroz izradu i dostavljanje sadržaja, komunikaciju, interakciju, testove i kvizove i dr.

Danas postoji veliki broj besplatnih (freeware) LMS-ova, ili courseware-alata, za koje se kaže da su open source (otvorenog kôda) varijante, ali i komercijalnih softvera, tj. onih koji se plaćaju. Najzastupljeniji besplatni courseware-alati Moodle, Claroline, Atutor, ILIAS podržavaju "OpenSource"-filozofiju, što znači da obezbeđuju softver čiji je izvorni kod, u nekom programskom jeziku, dostupan u okviru "open source" licence. Korisnici ovih alata mogu menjati, prepravljati, poboljšavati njegov sadržaj i prilagoditi ga svojim potrebama, što nije slučaj sa plaćenim softverom.

Najpoznatiji primeri komercijalnih courseware-alata su WebCT, BlackBoard i IntraLearn, koji, za razliku od besplatno dostupnih alata obezbeđuju: privatni prostor i postavke, bolju asinhronu i sinhronu komunikaciju, interni e-mail, korišćenje kalendara, izbor izgleda interfejsa, više mogućnosti u proveri znanja, podršku za audio i video sadržaje, podršku za razmenu sadržaja i dr.

Jedan od najzasupljenijih je Moodle open-source Sistem za upravljanje kursevima (Course Management System-CMS), takođe poznat i kao Sistem za upravljanje učenjem (Learning Management System- LMS) ili Virtuelno okruženje za učenje (Virtual Learning Environment-VLE) koji koriste univerziteti, škole i individualni instruktori, pre svega, radi kreiranja i unapređivanja kurseva pomoću veb-tehnologija.

U skladu sa specifičnim ciljevima realizacije nastave stranih jezika, analizom navedenih alata, sa aspekta pojedinih internet servisa i sadržaja relevantnih za postizanje efektivnih rezultata u online okruženju, može se uočiti da rad u okviru diskusija, debata i foruma, kao i upravljanje njihovim sadržajem na nivou kursa podržavaju svi prethodno navedeni sistemi za e-učenje. Komunikacija putem elektronske pošte (e-mail) i mailing liste najefikasnije se prezentuje za korisnike Moodle platforme, dok ostali sistemi ne obezbeđuju optimalan broj administrativnih podešavanja za određene opcije. Kalendar događaja, struktuiran na Moodle platformi, omogućava prikaz događaja vezanih za svaki predmet pojedinačno, dok kod ostalih sistema to nije slučaj. Administrativni alati za kreiranje i upravljanje sadržajem su podržani u svim opisanim sistemima. Iz ugla bezbednosti, zaštite i anonimnosti, autentifikacija je realizovana na osnovnom nivou na svim opisanim platformama, s tim što Moodle platforma omogućava enkripciju sesije, odnosno, šifrovanje i dešifrovanje podataka korišćenjem standardnih protokola za zaštitu podataka. 
Prema mogućnostima kreiranja testova, Moodle platforma nudi najveći broj različito struktuiranih tipova pitanja, kao i po tehničkim karakteristikama opisa korišćenja informacione arhitekture, podrške različitim vrstama baza podataka i sistema za upravljanje bazom podataka.

Moodle sistem, kreiran poštujući pedagoške principe, prednjači i sa aspekta kvaliteta interakcije nastavnika i studenata, interakcije između samih studenata, unapređenja motivacije i samostalnosti studenata, itd., što je od izuzetnog značaja za nastavu stranih jezika na visokoškolskoj ustanovi gde broj studenata u grupama u većini slučajeva prevazilazi uobičajene standarde.

\section{REZIME}

Efikasnost navedenih sistema i coursware-alata za e-učenje u cilju postizanja ciljeva specifičnih za nastavu stranih jezika u velikoj meri zavisi od načina njihovog korišćenja i uređenja. Online-aktivnosti koje se realizuju pomoću ponuđenih alata u virtuelnom okruženju moraju biti tako strukurisane da odgovaraju definisanim fazama interaktivnog učenja u skladu sa postavljenim ciljevima u smislu ostvarenja odgovarajućih ishoda učenja. To znači da pojedine alate s jedne strane ne treba koristiti proizvoljno, već analogno jezičkoj veštini koja se prezentuje ili uvežbava, ali i da, s druge strane, učesnici u procesu učenja moraju biti svesni njihove funkcije.

U nastavi stranih jezika posebnu primenu imaju asinhorini veb-alati kao što su mejl, forum, blog i podkast, i sinhroni kao na primer veb-telefonija (Skype), chat i video-konferencije. Zajednički rad na tekstu, kako u sinhronom, tako i u asinhronom vidu omogućavaju takozvani tekst-editori, od kojih je do sada bio najzastupljeniji wiki. Dokumenti se mogu sinhrono obrađivati i na Google Docs, dok se na YouTube-u ili Flickr-u može naći raznovrstan nastavni materijal ili pak objaviti i komentarisati sopstvene video-klipove i fotografije.

Pored veb-alata i platformi, internet kao globalna mreža nudi obilje sadržaja, koji, ukoliko se pažljivo biraju, iniciraju autentične komunikativne situacije. U nastavnom kontekstu ti resursi sa tehničke strane omogućuju online-učenje, a sa sadržajne podstiču pismene i usmene komunikativne kompetencije i interakciju, u uže jezičkom i u širem socijalnom smislu. Wiki na primer služi, osim za prezentovanje sadržaja u okviru zadataka, i da učesnici zajednički pišu tekstove različitih vrsta (eseje, recenzije, prikaze) i daju feedback, sastavljaju i razmenjuju liste interesantnih linkova, izrađuju različite prezentacije, organizuju grupni rad, vode lični dnevnik ili protokol aktivnosti etc. Za uvežbavanje usmenih jezičkih veština slušanja i govora u nastavi stranih jezika od velike pomoći su podkasti, jer oni osim autentičnih primera korišćenja stranog jezika nude i obilje sociokulturoloških tema. Osim toga, učesnici imaju mogućnost da kreiraju i objavljuju i sopstvene priloge.
Zaključno se može reći da je za produktivno korišćenje internet-servisa i sadržaja, pored stručnih, jezičko-metodičkih znanja i veština potrebno obezbediti i razvijati kod svih učesnika u nastavnom procesu i medijsku kompetenciju. To se ne odnosi samo na poznavanja tehničkih uslova za realizaciju e-učenja, u smislu rukovanja hardverom i softverom, već na medijsku kompetenciju kao ključnu životnu veštinu. Ona obuhvata znanja o pojedinim LMS-sistemima i courseware-alatima, poznavanje mogućnosti njihove implementacije u nastavnom procesu i sposobnost kreiranja adekvatnih online-aktivnosti ( $E$ tivity) u skladu sa odgovarajućim fazama online-učenja (kao na primer sa predstavljenim modelom Gilly Salmon), ali i sposobnost kritičkog sagledavanja prednosti i mana učenja u virtuelnom okruženju.

\section{LITERATURA}

Fallon, C., \& Brown, S. (2003). E-learning standards: A guide to purchasing, developing, and deploying standards-conformant e-learning. Boca Raton, FL: St. Lucie Press.

Cohn, R.C. (2009). Von der Psychoanalyse zur themenzentrierten Interaktion. Stuttgart: Klett-Cotta.

Häfele, H., \& Maier-Häfele, K. (2004). 101 e-learning-Seminarmethoden: Methoden und Strategien für die Online- und blended-learning-Seminarpraxis. Bonn: ManagerSeminareVerl.-GmbH.

Maier-Häfele, K., \& Häfele, H. (2005). Open-Source-Werkzeuge für e-Trainings: Übersicht, Empfehlungen und Anleitungen für den sofortigen Seminareinsatz. Bonn: ManagerSeminare-Verl.-GmbH.

Paramythis, A., \& Loidl-Reisinger, S. (2004). Adaptive Learning Environments and e-Learning Standards. Electronic Journal of e-Learning. 2, (1), 181-194.

Perraton, H. (2000). Open and Distance Learning in the Developing World. London: Routlege.

Rivers, W. M. (1987). Interactive language teaching. Cambridge [Cambridgeshire: Cambridge University Press.

Rösler, D., \& Würffel, N. (2014). Lernmaterialien und Medien. München: Klett-Langenscheidt.

Salmon, G. (2004). E-tivities. Zürich: Orell Füssli Verlag AG.

Salmon, Gilly. The five stage model. Preuzeto sa http://www. gillysalmon.com/five-stage-model.html

Schart, M., Legutke, M. (2012). Lehrerkompetenz und Unterrichtsgeatlatung. München: Klett-Langenscheidt.

USDLA. (2015). The United States Distance Learning Association. Preuzeto sa www.usdla.org

Weber, H. (1998). Interaktiver Fremdsprachenunterricht: Definitionen, Formen, Funktionen. Zielsprache Englisch, 28, 5-10. 